\title{
TESTING RANDOM WALK HYPOTHESIS FOR ISTANBUL STOCK EXCHANGE
}

\author{
DOI: 10.17261/Pressacademia.2019.1063 \\ PAP-V.9-2019(10)-p.48-53
}

\section{Oktay Tas ${ }^{1}$, Cigdem Guleroglu Atac ${ }^{2}$}

${ }^{1}$ Istanbul Technical University, Department of Management, 34367, Istanbul, Turkey. tasokta@itu.edu.tr, ORCID: 0000-0002-7570-549X

${ }^{2}$ Istanbul Technical University, Department of Management, 34367, Istanbul, Turkey. gulerogluatac16@itu.edu.tr, ORCID:0000-0003-2367-0878

\begin{abstract}
Purpose- This study investigates weak form market efficiency of Istanbul Stock Exchange (ISE) via Random Walk Hypothesis (RWH).

Methodology- Two random walk tests, Dickey-Fuller and Runs test are used to search for random walk in stock market. Natural log returns of BIST-30 index firms, BIST-30 index, participation index firms and participation index are analysed by both tests over a five year period from 2013 to 2018. Therefore, BIST30 index returns together with BIST100 and BISTTUM indexes are analysed in a longer period from 2000 to 2018 including 2001 and 2008 financial crises in Turkey.

Findings- Weak form market efficiency is justified according to Dickey Fuller test, but not for Runs test.

Conclusion- While Dickey Fuller test results reject random walk in ISE, which leads that weak form market efficiency is not justified; Runs test are failed to give certain results on market efficiency for the same data set and time period.
\end{abstract}

Keywords: Market efficiency in weak form, Dickey Fuller random walk test, runs test, Istanbul Stock Exchange Indexes, efficient market hypothesis.

JEL Codes: G30, G32

\section{INTRODUCTION}

With financial markets becoming more and more important every day, the concept of effectiveness has become much more crucial than ever. According to Efficient Market Hypothesis (EMH), reflection of a relevant information to financial instrument specifies the forms of market. There are three types of market forms which are; weak form, semi strong form and strong form. Parallel to EMH, technical analysis, public information, and private information are no of use for weak form, semi strong form and strong form, respectively.

As an attractive emerging stock market, Istanbul Stock Exchange (ISE) has gained considerable interest from both academics and financial experts since last decades. Thus, market efficiency becomes an important concept. It is a common and efficient way to search for a random walk process in order to understand the market efficiency. If a stock price or market index follow random walk that prevents investors from earning abnormal returns, then it is convenient to say that market is efficient.

In this study, natural log returns of BIST-30 index firms, BIST-30 index, participation index firms and participation index are analysed by both Dickey-Fuller unit root test and Runs test over a five year period from 2013 to 2018. Therefore, we develop the study into a longer period from 2000 to 2018 including 2001 and 2008 financial crises in Turkey by examining BIST30 index returns together with BIST100 and BISTTUM indexes. The results shows that weak form market efficiency is justified according to Dickey Fuller test, but not for Runs test. Thus, it is concluded that while Dickey Fuller test results reject random walk in ISE, which leads that weak form market efficiency is not justified; Runs test are failed to give certain results on market efficiency for the same data set and time period.

\section{LITERATURE REVIEW}

The randomness of stock prices is one of the most challenged remedies of the finance literature from both theoretical and practical viewpoints. The fundamental null hypothesis of stock returns have correlation and follow random walk through time has been tested thoroughly applying couple statistical methods, mostly unit root or RUNS tests for major developed markets. Among many others, the pioneering studies of Grossman and Stiglitz (1980); Campbell et al (1997); Lo (2004); Lim (2007); Ito and Sugiyama (2009); Smith (2012) and Urguhart et al (2015) confirmed the statistically significant return predictability. On the other hand, there exist a considerable amount of studies as well advocating the random walk and market efficiency of well-known stock markets. They can be exemplified as: Chan and Gup 
(1992); Cai et al (2005); Pham et al (2007); Liu (2010); Hamid et al (2010); Onali and John (2011) and Khrapko (2013). One crucial intuition behind the conflicting findings may result from using different econometric techniques and structural breaks/time-varying nature of data sets. Even most of the quantitative studies have been conducted for mature developed markets so far because of the robust firm and country specific data for variables; emerging and frontier countries have recently got paid interest of researchers. Urrutia (1995) for Argentina (+); Ely (2011) for Brazil (-); Lim et al (2013) for China (+); Kumar and Kumar (2015) for India (-); Jefferis and Graham (2005) for South Africa (+) and Niemczak and Smith (2013) for Middle East Stock Markets (-) can be named by countries particularly. Nonetheless, inconsistency of EMH conformity is valid for emerging markets as well which shown by +/- signs in brackets for countries. To adhere the purpose of this study, the limited Turkish literature is particularly scrutinized. Consistent with relevant prior research, an absolute judgement regarding random walk behavior cannot be concluded for Turkish Stock Market Borsa Istanbul. (eg. Balaban, 1995; Tas and Dursunoglu, 2005; Cevik and Erdogan, 2009; Ergul, 2009; Altunoz, 2016 and Aytekin and Erol, 2017).

\section{DATA AND METHODOLOGY}

In order to search the existance of market efficiency in weak form, we prefered to use two widely used random walk tests Dickey-Fuller and Runs test in the light of the study Tas and Dursunoglu (2005). For the overall analysis, the stock content and weights of BIST30, BIST100 and BISTTUM indexes are assumed to be same as the beginning of the period. Since the participation index is a relatively new index in ISE, we keep the current form of the index during the overall period. First, we employ Dickey-Fuller unit root test on natural log returns of stock prices of BIST30 index firms, daily BIST30 index price, prices of participation index firms and participation index prices on daily basis. Second, we apply Dickey-Fuller unit root test on natural log returns of daily BIST30, BIST100 and BISTTUM index prices. Another well known approach to detect statistical efficiencies which means randomness, is Runs test. This test is performed by examining a time series for returns of a security and testing whether the number of consecutive price gains or drops shows a pattern. In the following table, there are price differences of BIST30 index stocks during the period 2013-2018. Positive return is shown with a "+" sign, negative return is shown with "-" sign, and no change in return is shown with "0" in Table 1.

Table 1: Positive, Negative and Zero Change Returns of BIST30 Index Stocks in 2013-2018

\begin{tabular}{|c|c|c|c|}
\hline Stocks & + & - & 0 \\
\hline AKBNK & 600 & 620 & 96 \\
\hline ARCLK & 593 & 619 & 104 \\
\hline ASELS & 616 & 570 & 130 \\
\hline ASYAB & 214 & 263 & 839 \\
\hline BIMAS & 626 & 606 & 84 \\
\hline $\mathrm{DOHOL}$ & 418 & 458 & 440 \\
\hline EKGYO & 553 & 579 & 184 \\
\hline ENKAI & 613 & 575 & 128 \\
\hline EREGL & 633 & 579 & 104 \\
\hline GARAN & 612 & 626 & 78 \\
\hline HALKB & 625 & 594 & 97 \\
\hline IHLAS & 310 & 370 & 636 \\
\hline ISCTR & 615 & 605 & 96 \\
\hline $\mathrm{KCHOL}$ & 590 & 604 & 122 \\
\hline KOZAA & 541 & 638 & 137 \\
\hline KOZAL & 640 & 614 & 62 \\
\hline KRDMD & 539 & 564 & 213 \\
\hline MGROS & 610 & 612 & 94 \\
\hline PETKM & 624 & 559 & 133 \\
\hline PGSUS & 616 & 619 & 81 \\
\hline SAHOL & 602 & 612 & 102 \\
\hline SISE & 614 & 573 & 129 \\
\hline TAVHL & 624 & 597 & 95 \\
\hline TCELL & 622 & 576 & 118 \\
\hline THYAO & 627 & 600 & 89 \\
\hline TOASO & 598 & 621 & 97 \\
\hline TTKOM & 596 & 612 & 108 \\
\hline TUPRS & 663 & 571 & 82 \\
\hline VAKBN & 619 & 605 & 92 \\
\hline YKBNK & 581 & 614 & 121 \\
\hline
\end{tabular}

For the random walk analysis, we first employ Runs test on natural log returns of stock prices of BIST30 index firms, BIST30 index price, participation index firms and participation index price data on daily basis between 2013-2018. Second, we apply Runs test on natural log returns of daily BIST30, BIST100 and BISTTUM index prices in a longer period 2000-2018. The following table shows variable definitions of Runs Test presented in the emprical results of the next section. 
Table 2: Variable Definitions of Runs Test

\begin{tabular}{|l|l|}
\hline \multicolumn{2}{|l|}{ Concepts and Variables used in Runs Test } \\
\hline Definition & Abbreviation \\
\hline Number of Runs & R \\
\hline Number of Zeros & NO \\
\hline Number of Ones & N1 \\
\hline Total Observation & N \\
\hline Expected Runs & Ex. R \\
\hline The Variance of Runs & Var R \\
\hline The Standart Deviation of Runs & Stdev R \\
\hline Z-score & Z \\
\hline
\end{tabular}

\section{FINDINGS AND DISCUSSIONS}

\subsection{Empirical Results for Dickey-Fuller Test (ADF)}

Dickey-Fuller unit root test results on natural log returns of daily stock prices of BIST30 index firms, daily BIST30 index price, daily prices of participation index and daily participation index price is shown in Table 3, where KATLM stands for participation index.

Table 3: Dickey-Fuller Test (ADF) Results I

\begin{tabular}{|c|c|c|c|c|c|}
\hline BIST30 Firms & ADF Test Value & KATLM Firms & ADF Test Value & Indexes & ADF Test Value \\
\hline AKBNK & $-37,2780$ & AKCNS & $-28,5545$ & BIST30 & $-37,2155$ \\
\hline ARCLK & $-36,5541$ & ALBRK & $-14,2110$ & KATLM & $-35,7988$ \\
\hline ASELS & $-13,3064$ & ALKIM & $-35,8310$ & & \\
\hline ASYAB & $-10,1873$ & ANELE & $-34,4591$ & & \\
\hline BIMAS & $-28,3140$ & ASELS & $-13,4711$ & & \\
\hline DOHOL & $-34,9694$ & AYGAZ & $-36,0816$ & & \\
\hline EKGYO & $-27,8923$ & BIMAS & $-28,4370$ & & \\
\hline ENKAI & $-20,7573$ & BUCIM & $-35,6670$ & & \\
\hline EREGL & $-36,5323$ & CEMTS & $-17,1100$ & & \\
\hline GARAN & $-39,3425$ & EGEEN & $-38,8937$ & & \\
\hline HALKB & $-37,4927$ & ERBOS & $-38,8631$ & & \\
\hline IHLAS & $-28,2415$ & EREGL & $-7,3105$ & & \\
\hline ISCTR & $-14,2245$ & FLAP & $-29,2206$ & & \\
\hline $\mathrm{KCHOL}$ & $-37,9101$ & FROTO & $-38,0814$ & & \\
\hline KOZAA & $-33,9220$ & GENTS & $-36,8822$ & & \\
\hline KOZAL & $-36,3052$ & GOODY & $-23,8440$ & & \\
\hline KRDMD & $-7,3140$ & IHLGM & $-17,9772$ & & \\
\hline MGROS & $-13,6373$ & KARTN & $-14,1334$ & & \\
\hline PETKM & $-24,4858$ & KONYA & $-17,1925$ & & \\
\hline PGSUS & $-14,3505$ & LOGO & $-11,0500$ & & \\
\hline SAHOL & $-37,3455$ & OZGYO & $-12,5735$ & & \\
\hline SISE & $-22,9905$ & PNSUT & $-24,1659$ & & \\
\hline TAVHL & $-27,5087$ & SELEC & $-38,6506$ & & \\
\hline TCELL & $-17,9124$ & TATGD & $-25,1085$ & & \\
\hline THYAO & $-13,2623$ & TMSN & $-11,6559$ & & \\
\hline TOASO & $-15,6673$ & VESBE & $-27,6524$ & & \\
\hline TTKOM & $-36,9437$ & YATAS & $-26,4556$ & & \\
\hline TUPRS & $-17,6530$ & & & & \\
\hline VAKBN & $-13,4579$ & & & & \\
\hline YKBNK & $-37,4965$ & & & & \\
\hline
\end{tabular}

Dickey-Fuller unit root test is applied to each return series at level and ADF test values of each stock are found to be less than critical values at each $1 \%, 5 \%$ and $10 \%$ significence level. Thus, all return series has no unit root and random walk hypothesis is rejected. This results in the rejection of market efficiency in weak form. An example of critical values for AKBNK stock at each $1 \%, 5 \%$ and $10 \%$ significence level are shown in Table 4. 
Table 4: Critical Values for AKBNK Stock at each 1\%, $5 \%$ and $10 \%$ Significence Levels

\begin{tabular}{|c|c|}
\hline Significance level & Test critical values for AKBNK \\
\hline 1\% level & $-3,9650$ \\
$5 \%$ level & $-3,4132$ \\
$10 \%$ level & $-3,1286$ \\
\hline
\end{tabular}

Furthermore, we apply the same analysis on natural log returns of daily BIST30, BIST100 and BISTTUM index prices. The results are shown in Table 5 where Pr represents the results for price data, $L N$ is for natural logaritm of prices and Rt is for log returns of prices. According to the results, log returns of BIST30, BIST100 and BISTTUM index data has no unit root, in other words, they are stationary. Therefore, the random walk hypothesis is rejected which shows the existence of market inefficiency. Furthermore, this result is valid for the each selected time period. The periods are determined based on the financial crises time in Turkey where abnormal price returns are realised, in order to verify our findings under the effect of crises.

Table 5: Dickey-Fuller Test (ADF) Results II

\begin{tabular}{|c|c|c|c|c|c|c|c|c|c|}
\hline \multirow{2}{*}{ TL } & \multicolumn{3}{|c|}{ BIST-30 } & \multicolumn{3}{c|}{ BIST-100 } & \multicolumn{3}{c|}{ BIST-TUM } \\
\cline { 2 - 9 } & $\operatorname{Pr}$ & LN & Rt & Pr & LN & Rt & Pr & LN & Rt \\
\hline 2000-2018-ADF & $-3,7090$ & $-2,7897$ & $-20,6897$ & $-3,6350$ & $-2,7867$ & $-20,3460$ & $-3,6105$ & $-2,7476$ & $-20,1929$ \\
\hline 2008-2018-ADF & $-3,0904$ & $-2,7183$ & $-16,0030$ & $-2,9821$ & $-2,5435$ & $-15,6710$ & $-2,9517$ & $-2,4809$ & $-15,6300$ \\
\hline 2013-2018-ADF & $-2,5838$ & $-2,7534$ & $-12,3864$ & $-2,4727$ & $-2,6455$ & $-12,3330$ & $-2,4346$ & $-2,6305$ & $-12,3523$ \\
\hline Critical Value at \%5 & \multicolumn{9}{|c|}{$-\mathbf{3 , 4 1 3 5}$} \\
\hline
\end{tabular}

\subsection{Empirical Results for Runs Test}

Runs test results on natural log returns of daily stock prices of BIST30 index firms and daily BIST30 index price are shown in Table 6 . Runs test results on natural log returns of daily prices of participation index firms and daily participation index price are shown in Table 7, where KATLM stands for participation index.

Table 6: Runs Results I for BIST30 Index and Index Firms

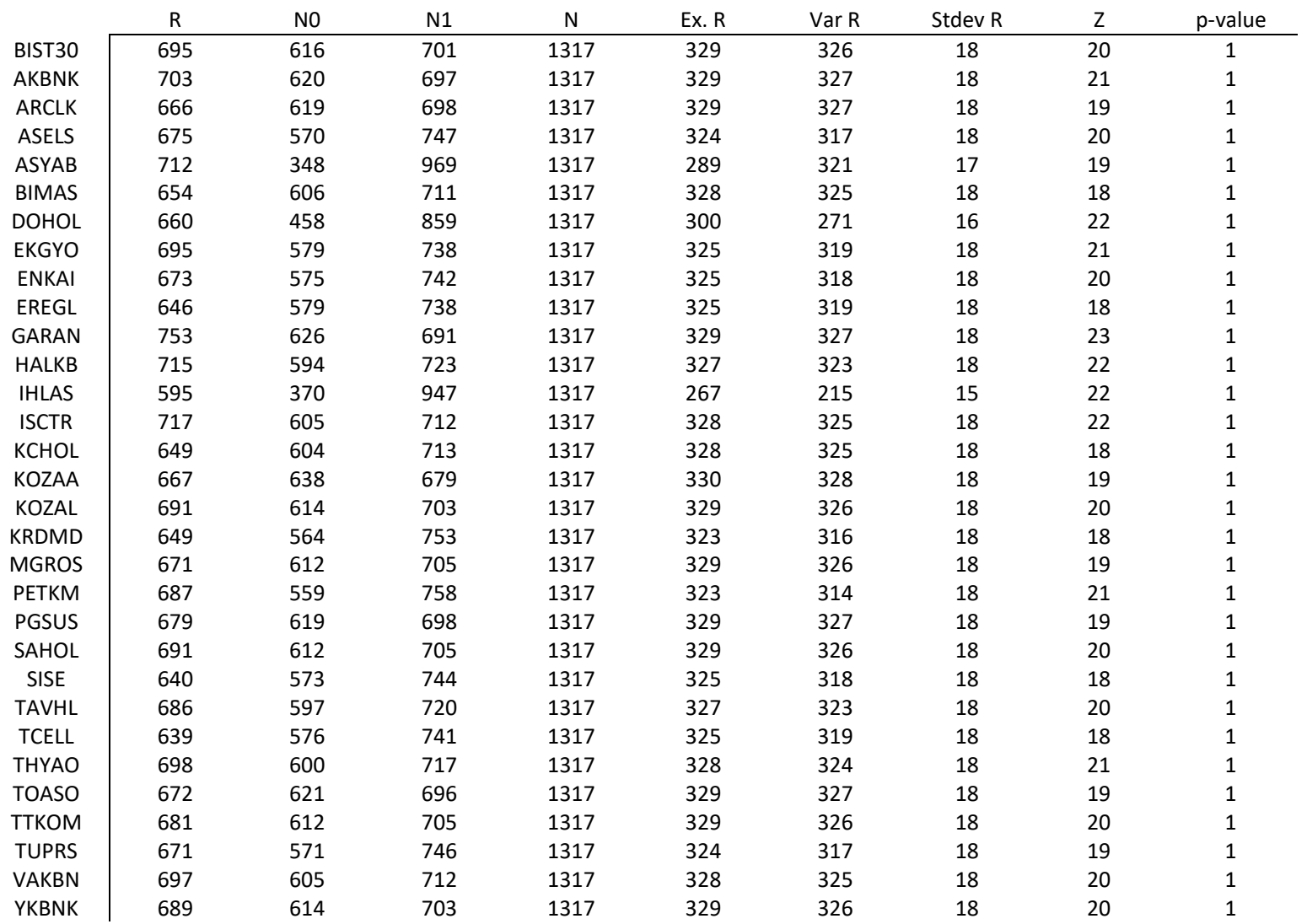


Table 7: Runs Results I for Participation Index and Index Firms

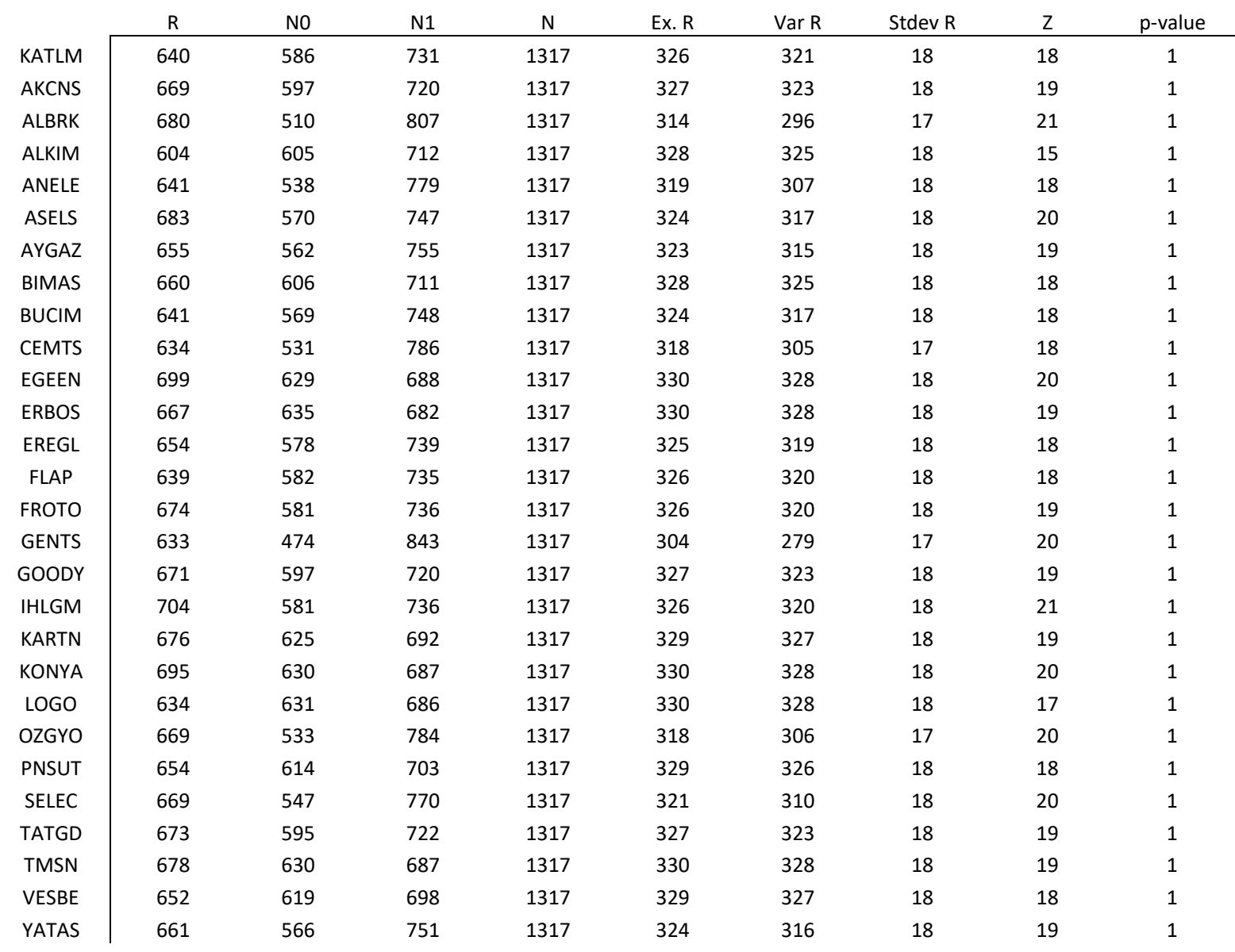

In Table 6 and Table 7, p-values are found to be very close to 1, which means it is higher than the significance level of $5 \%$. Thus, random walk hypothesis can not be rejected. Consequently, it is not possible to make a certain comment on the existence of market efficiency via random walk hypothesis and Runs test. Similarly, we apply the Runs test analysis on natural log returns of daily BIST30, BIST100 and BISTTUM index prices in a longer period 2000-2018. The results are shown in Table 8. According to results in Table 8, since p-values are higher than the significance level $5 \%$, data seems to follow random walk. Thus, it is again not possible to be sure if the market is efficient or not, by the Runs test analysis method. Consequently, for our analysis and empirical result, Runs test results do not agree with the Dickey-Fuller test results.

\section{Table 8: Runs Results II}

\begin{tabular}{|c|c|c|c|c|c|}
\hline \multicolumn{6}{|c|}{ BIST-30 } \\
\hline & Expected & Observed & St Dev & Test Stat & $\mathrm{p}$-value \\
\hline $2000-2018$ & 2.372 & 2.404 & 34,43 & 0,92 & 0,3578 \\
\hline 2008-2018 & 1.374 & 1.374 & 26,19 & 0,00 & 0,9970 \\
\hline 2013-2018 & 765 & 745 & 19,27 & 1,06 & 0,2889 \\
\hline \multicolumn{6}{|c|}{ BIST-100 } \\
\hline & Expected & Observed & St Dev & Test Stat & $\mathrm{p}$-value \\
\hline $2000-2018$ & 2.410 & 2.371 & 34,41 & 1,13 & 0,2577 \\
\hline 2008-2018 & 1.390 & 1.373 & 26,17 & 0,65 & 0,5174 \\
\hline 2013-2018 & 779 & 744 & 19,27 & 1,80 & 0,0726 \\
\hline \multicolumn{6}{|c|}{ BIST-TUM } \\
\hline $2000-2018$ & Expected & Observed & St Dev & Test Stat & $\mathrm{p}$-value \\
\hline 2008-2018 & 2.400 & 2.371 & 34,41 & 0,84 & 0,3995 \\
\hline \multirow[t]{2}{*}{ 2013-2018 } & 1.382 & 1.373 & 26,17 & 0,36 & 0,7206 \\
\hline & 779 & 744 & 19,26 & 1,80 & 0,0715 \\
\hline
\end{tabular}




\section{CONCLUSION}

In this study, we aim to investigate weak form market efficiency of Istanbul Stock Exchange (ISE) via Random Walk Hypothesis (RWH). Two well-known random walk tests, Dickey-Fuller and Runs test are used to search for random walk in stock market. Natural log returns of BIST30 index firms, BIST-30 index, participation index firms and participation index are analysed by both Dickey-Fuller unit root test and Runs test over a five year period from 2013 to 2018. Therefore, we develop the study into a longer period from 2000 to 2018 including 2001 and 2008 financial crises in Turkey by examining BIST30 index returns together with BIST100 and BISTTUM indexes. The results shows that weak form market efficiency is justified according to Dickey Fuller test, but not for Runs test. Thus, it is concluded that while Dickey Fuller test results reject random walk in ISE, which leads that weak form market efficiency of ISE is not justified. On the other hand, Runs test are failed to give certain results on market efficiency for the same data set and time period in ISE.

\section{REFERENCES}

Aytekin, S. \& Erol, A. (2017). A Testing the Weak-Form Market Efficiency on the Borsa Istanbul (BIST) Sustainability Index (XUSRD): Runs Test Application. International Journal of Business and Management Invention, Volume 6, Issue 5, pp. 68-75.

Balaban, E. (1995, February). Informational Efficiency of the Istanbul Securities Exchange and Some Rationale for Public Regulation. The Central Bank of the Republic of Turkey, Discussion Paper No: 9502, 1-27.

Cai, B. M., Cai, C. X. \& Keasey, K. (2005). Market efficiency and returns to simple technical trading rules: further evidence from U.S., U.K., Asian and Chinese stock markets. Asia-Pacific Financial Markets, 12(1), 45-60.

Chan, K. \& Gup, B. (1992). An empirical analysis of stock prices in major Asian markets and the United States. The Financial Review, 27(2), 289-307.

Ely, R. A. (2011). Returns predictability and stock market efficiency in Brazil. Brazilian Review of Finance, 9(4), 571-584.

Grossman, S. J., Stiglitz, J. E. (1980). On the impossibility of informationally efficient markets. The American Economic Review, 70(3), 393408.

Hamid, K., Suleman, M. T., Shah, S. \& Akash, R. (2010). Testing the weak form of efficient market hypothesis: empirical evidence from AsiaPacific markets. International Research Journal of Finance and Economics, 58, 121-133..

Jefferis, K., \& Graham, S. (2005). The changing efficiency of African stock markets. South African Journal of Economics, 73(1), 54-67.

Karahan, M., \& Alsu, E. (2016). Are the eastern European markets efficient? Evidence from nonlinear unit root test. International Journal of Academic Research in Economics and Management Sciences. 5(4): 252-263.

Khrapko, V. (2013). Testing the weak-form efficiency hypothesis in the Ukranian stock markets versus those of the USA, Russia, and Poland. Ekonomika, 92(2), 108-121.

Kumar, S., \& Kumar, L. (2015). Market efficiency in India: an empirical study of random walk hypothesis of Indian stock market - NSE midcap. ZENITH International Journal of Multidisciplinary Research, 5(1), 167-177.

Lim, T. C., Huang, W., Yun, J. L., \& Zhao, D. (2013). Has stock market efficiency improved? Evidence from China. Journal of Finance \& Economics, 1(1), 01-09.

Onali, E. \& John, G. (2011). Are European equity markets efficient? New evidence from fractal analysis. International Review of Financial Analysis, 20(2), 59-67.

Pham, V., Nguyen, D. \& Tô, T. (2007). Abnormal returns after large stock price changes: evidence from Asia-Pacific markets.

Tas, O., \& Dursunoglu, S. (2005). Testing Random Walk Hypothesis for Istanbul Stock Exchange. International Trade and Finance Association 15th International Conference (s. 1-17). Istanbul: International Trade and Finance Association Conference Papers.

Urrutia, J. L. (1995). Tests of random walk and market efficiency for Latin American emerging equity markets. The Journal of Financial Research, 18(3), 299-309. 